\title{
ANALISIS PERUBAHAN GARIS PANTAI DAN STRATEGI PENGELOLAANNYA DI PANTAI BARAT SULAWESI SELATAN
}

\author{
Coastline Change Analysis and Management Strategies on the West Coast of \\ South Sulawesi \\ Agustina 1), Abdul Rauf ${ }^{2)}$ dan Asbar ${ }^{2)}$ \\ 1) Mahasiswa Pascasarjana Universitas Muslim Indonesia \\ 2) Program Studi Manajemen Pesisir dan Teknologi Kelautan PPS-UMI Makassar
}

Korespondensi: agustina_aghu@yahoo.com

Diterima: tanggal 2 November 2018; Disetujui 25 November 2018

\begin{abstract}
This study aims to: (1) analyze changes in coastlines that experience accretion and coastal abrasion; (2) analyze oceanographic factors that influence changes in coastline; (3) formulate direction of management strategies in the research areas that experience accretion and abrasion. In addition, it is expected to be able to provide information to stakeholders as a material consideration in taking the policy of managing the coastal areas of Pangkep and Pinrang Regencies. The method used in this study is analysis of shoreline changes based on survey and mapping methods, interpretation of SPOT 6 images for shoreline changes and SWOT analysis for strategy direction determination. The results of image interpretation show that the extent of shoreline changes that occurred in Pangkep Regency amounted to $38.74 \mathrm{Ha}$ in the form of accretion and $13.99 \mathrm{Ha}$ in the form of abrasion, whereas for Pinrang Regency the extent of shoreline change was $158.15 \mathrm{Ha}$ which experienced accretion and $41.88 \mathrm{Ha}$ in the form of abrasion. The results of the Coastal Coastal Management Strategy analysis based on the results of the analysis carried out there are 4 things that become tactical decisions for recommendations in coastal management efforts, namely; make special areas for coastal security and coastal conservation naturally; law enforcement and institutional strengthening; provide special allocation of space for safeguards and coastal protection; improving the quality of human resources around the coast.
\end{abstract}

Keywords: Coastline, Abrasion, Accretion, SPOT, SWOT

\begin{abstract}
ABSTRAK
Penelitian ini bertujuan untuk: (1) menganalisis perubahan garis pantai yang mengalami akresi dan abrasi pantai; (2) menganalisis faktor-faktor oseanografi yang berpengaruh terhadap perubahan garis pantai; (3) merumuskan arahan strategi pengelolaan pada wilayah penelitian yang mengalami akresi dan abrasi. Selain itu, diharapkan dapat memberikan informasi kepada stakeholder sebagai bahan pertimbangan dalam mengambil kebijakan pengelolaan wilayah pesisir pantai Kabupaten Pangkep dan Pinrang. Metode yang digunakan dalam penelitian ini yaitu analisis perubahan garis pantai berdasarkan metode survey dan pemetaan, interpretasi citra SPOT 6 untuk perubahan garis pantai dan analisis SWOT untuk penentuan arahan strategi. Hasil interpretasi citra menunjukkan bahwa luas perubahan garis pantai yang terjadi di Kabupaten Pangkep sebesar 38.74 Ha berupa akresi dan 13.99 Ha berupa abrasi, sedangkan untuk Kabupaten Pinrang luas perubahan garis pantai sebesar 158.15 Ha yang mengalami akresi dan $41.88 \mathrm{Ha}$ berupa abrasi. Hasil analisis Prioritas Strategi Pengelolaan Pesisir Pantai berdasarkan hasil analisis yang dilakukan ada 4 hal yang menjadi keputusan taktis untuk rekomendasi dalam upaya pengelolaan pesisir pantai, yaitu; membuat daerah khusus pengamanan pantai dan konservasi pantai secara alami; penegakan hukum dan penguatan kelembagaan; memberikan alokasi ruang khusus untuk pengaman dan perlingdungan pantai; peningkatan kualitas SDM masyarakat sekitar pesisir pantai.
\end{abstract}

Kata kunci: Garis Pantai, Abrasi, Akresi, SPOT, SWOT 


\section{PENDAHULUAN}

Wilayah pesisir merupakan wilayah yang sangat intensif dimanfaatkan untuk kegiatan manusia seperti kawasan pusat pemerintahan, pemukiman, industri, pelabuhan, pertambakan, perikanan, pariwisata dan sebagainya (Triatmodjo, 1999). Selanjutnya Rais (2000) mengemukakan bahwa wilayah pesisir merupakan wilayah yang sangat padat jumlah penduduknya. Di Indonesia sendiri $60 \%$ penduduknya hidup di wilayah pesisir, peningkatan jumlah penduduk yang hidup di wilayah pesisir memberikan dampak tekanan terhadap sumberdaya alam pesisir seperti degradasi pesisir, pembuangan limbah ke laut, abrasi, akresi pantai dan sebagainya.

Pantai Barat Sulawesi Selatan terdiri dari beberapa kabupaten pesisir antara lain: Kota Makassar, Kabupaten Maros, Pangkep, Barru, Parepare dan Pinrang. Beberapa daerah pesisir pantai tersebut dalam beberapa tahun terakhir telah mengalami perubahan salah satunya pesisir pantai Kabupaten Pangkep dan Pinrang.

Pesisir Kabupaten Pangkep dan Pinrang telah mengalami perubahan baik yang diakibatkan oleh faktor alam seperti terjadinya abrasi dan sedimentasi maupun akibat aktivitas manusia seperti; pemanfaatan lahan khususnya ekosistem pesisir sehingga terjadi kerusakan ekosistem dan adanya konversi hutan mangrove menjadi lokasi pertambakan, pembangunan pelabuhan, tambang dan pemukiman. Salah satu alternative untuk mengetahui perubahan garis pantai adalah menggunakan teknologi penginderaan jauh atau citra satelit. Pemanfaatan teknologi penginderaan jauh, banyak digunakan di wilayah pesisir mengingat informasi perubahan garis pantai sangat penting dalam berbagai kajian wilayah pesisir seperti rencana pengelolaan wilayah pesisir (Chand dan Acharya, 2010).

Berdasarkan uraian di atas, maka perlu dilakukan penelitian tentang kajian perubahan garis pantai serta arahan dan strategi pengelolaannya di Pantai Barat Sulawesi Selatan dengan pendekatan teknologi penginderaan jauh dan Sistem Informasi Geografis. Penelitian ini bertujuan untuk menganalisis perubahan garis pantai, faktor oseanografi yang berpengaruh terhadap perubahan garis pantai dan merumuskan strategi pengelolaannya. Hasil penelitian ini diharapkan dapat memberikan informasi bagi pengambil kebijakan di dalam merumuskan kebijakan terkait penanggulangan abrasi di sepanjang wilayah pesisir pantai barat Sulawesi Selatan khususnya di Kota Makassar, Kabupaten Maros, Pangkep, Barru, Parepare dan Pinrang karena daerah banyak mengalami perubahan garis pantai.

\section{METODE PENELITIAN}

Penelitian ini dilaksanakan pada bulan Agustus - September 2018 di Pantai Barat Sulawesi Selatan dengan lokasi pengamatan yaitu Kabupaten Pangkep dan Pinrang. Selengkapnya disajikan pada gambar berikut ini: 


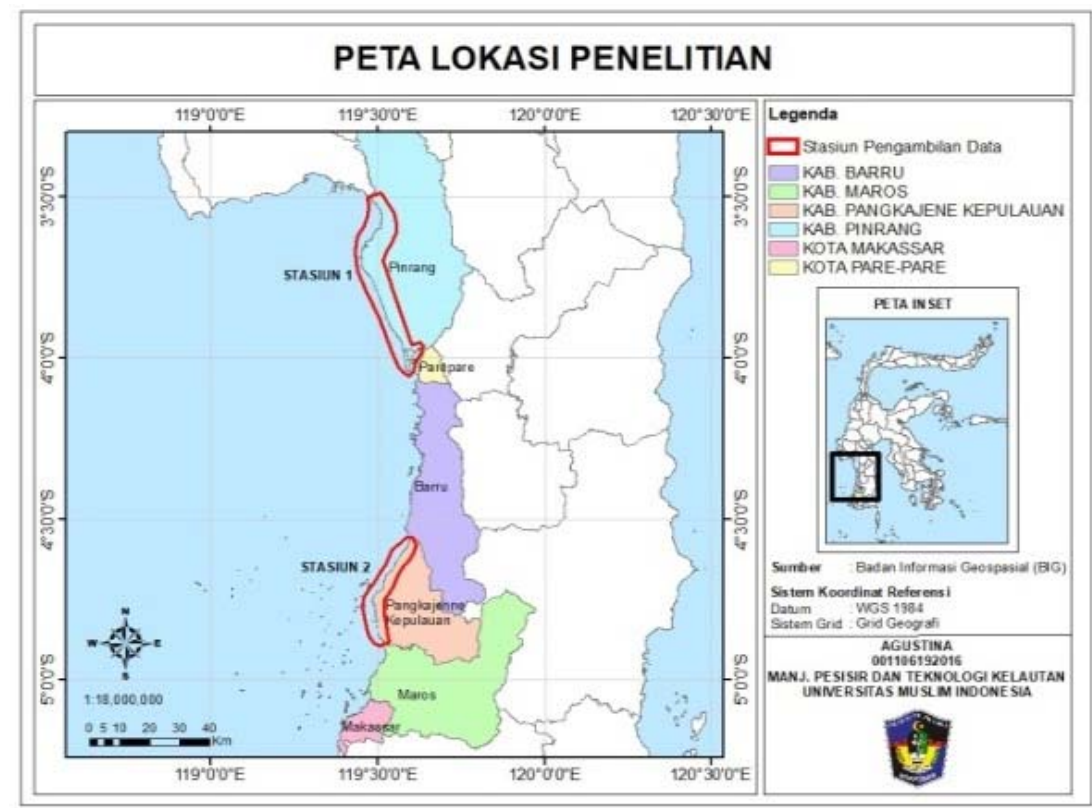

Gambar 1. Peta Lokasi Penelitian

Alat dan bahan yang digunakan dalam penelitian ini yaitu GPS untuk mengetahui posisi pengamatan, kamera untuk dokumentasi, personal computer untuk input data citra, software ArcGIS dan ER-Mapper untuk mengolah data citra, alat tulis menulis dan citra satelit Spot 6 tahun 2013-2018.

Penelitian ini menggunakan metode survei dan pemetaan. Pengumpulan data primer dilakukan dengan menggunakan metode interpretasi citra dan survei, sedangkan data sekunder diperoleh dari beberapa instansi terkait.

Penentuan responden pada masyarakat lokal dilakukan dengan teknik purpossive sampling artinya penentuan lokasi dan responden dengan beberapa pertimbangan tertentu oleh peneliti berdasarkan ciri atau sifat-sifat populasi yang sudah diketahui sebelumnya (Notoatmodjo, 2002).
Pertimbangan tertentu yang dimaksud adalah orang yang dijadikan responden mereka secara langsung terlibat dalam penanggulangan erosi dan sedimentasi dilokasi penelitian seperti tokoh masyarakat setempat, BAPPEDA, Dinas Kelautan dan Perikanan, Dinas PUPR dan Dinas Lingkungan Hidup dan masyarakat sekitar yang ada dilokasi penelitian.

Hasil pengumpulan data yang dilakukan selanjutnya dilakukan analisis berupa, analisis perubahan garis pantai. Perubahan garis pantai dianalisa dengan metode analisis spasial. Analisis perubahan garis pantai dilakukan dengan memperbandingkan secara tumpang susun data hasil system indraja dan data lapangan yang telah diinterpolasi menjadi data spasial.

Karakteristik hidrooseanografi, digunakan untuk data sekunder atau data pembanding dari data primer yang bersifat 
kuantitatif yang meliputi gelombang, arus dan pasang surut. Data gelombang, arus dan pasang surut diperoleh dari BMKG Stasiun Meteorologi Maritim Paotere Makassar.

Analisis SWOT (strength, weaknes, opportuniy and theart) digunakan untuk merumuskan strategi pengelolaan perubahan garis pantai, bersifat kualitatif dengan melakukan identifikasi secara sistematis terhadap berbagai faktor yang melingkupinya. Analisis didasarkan pada logika yang dapat memaksimalkan kekuatan (strength) dan peluang (opportunities), namun secara bersamaan dapat meminimalkan kelemahan (weakness) dan ancaman (threats). Adapun langkah-langkah yang dilakukan dalam analisis SWOT (strength, weaknes, opportuniy and theart) yaitu: (1) Identifikasi Kekuatan, Kelemahan, Peluang dan Ancaman; (2) Analisis SWOT; (3) Arahan Strategi Pengelolaan Hasil Analisa SWOT

\section{HASIL DAN PEMBAHASAN}

Kabupaten Pangkep terdiri dari 13 kecamatan (7 kecamatan terletak di wilayah pesisir, 4 kecamatan terletak di kepulauan dan 2 kecamatan terletak di pengunungan). Masyarakat pesisir Kabupaten Pangkajene dan Kepulauan pada umumnya adalah nelayan, pembudidaya, dan pengolah hasil perikanan. Kabupaten Pinrang terdiri dari daerah pantai, dataran dan pegunungan. Daerah pantai terdapat di 22 desa/ kelurahan berbatasan dengan Selat Makassar, yang berada di Kecamatan Lembang, Duampanua, Cempa, Mattiro Sompe, Lanrisang, dan Suppa.

Kondisi wilayah pesisir tidak dapat dilepaskan dari pengaruh kondisi sosial masyarakat yang bermukimam di sekitarnya, khususnya mengenai tingkat pendidikan, pengetahuan terhadap arti penting wilayah pesisir. Ekosistem yang ada di wilayah pesisir memiliki potensi sumberdaya alam yang serba guna dan dapat dimanfaatkan baik secara langsung maupun tidak langsung untuk peningkatan kesejahteraan masyarakat sekitarnya seperti usaha pertambakan, penangkapan ikan, penggunaan kayu dari mangrove untuk pembuatan rumah, wisata pantai dan sebagainya.

Data citra yang digunakan adalah data citra SPOT-6 yang sudah terkoreksi dengan perekaman pada tahun 2013 dan 2018 yang bebas dari gangguan awan sehingga mempermudah analisa. Peneliti mengunakan komposit band 321 untuk SPOT-6. Data yang diperoleh dari hasil pengolahan citra dan data sekunder disajikan ke dalam bentuk peta, diagram dan tabel yang sesuai dengan tujuan penelitian. Adapun tabel 1 panjang garis pantai Kabupaten Pangkep dan Pinrang pada tahun 2013-2018:

Tabel 1. Panjang garis pantai Kabupaten Pangkep dan Pinrang Tahun 2013-2018

\begin{tabular}{|l|c|c|c|}
\hline \multirow{2}{*}{ Kabupaten } & \multicolumn{2}{|c|}{ Panjang Garis Pantai $(\mathrm{Km})$} & \multirow{2}{*}{ Perubahan } \\
\cline { 2 - 3 } & 2013 & 2018 & \\
\hline Pangkep & 57.09 & 58.87 & 1.78 \\
\hline Pinrang & 98.02 & 98.51 & 0.49 \\
\hline
\end{tabular}


Sumber: Hasil Penelitian, 2018

Berdasarkan Tabel 1 yang disajikan diatas dapat dilihat bahwa panjang garis pantai Kabupaten Pangkep pada tahun 2013 sepanjang $57,09 \mathrm{~km}$, garis pantai pada tahun 2018 bertambah sepanjang 1,78 $\mathrm{km}$ menjadi 58,87 km. Sedangkan panjang

Tabel 2. Perubahan garis pantai pesisir Kabupaten Pangkep dan Pinrang

\begin{tabular}{|l|c|c|c|}
\hline \multicolumn{1}{|c|}{ Kabupaten } & Tahun & Abrasi (Ha) & Akresi (Ha) \\
\hline Pinrang & $2013-2018$ & 41,88 & 158,15 \\
\hline Pangkep & $2013-2018$ & 13,99 & 38,74 \\
\hline
\end{tabular}

Sumber: Hasil Penelitian, 2018

Berdasarkan luas perubahan garis pantai yang disajikan pada Tabel 2, dapat dilihat bahwa luas perubahan garis pantai Kabupaten Pangkep berupa akresi sebesar $38,74 \mathrm{Ha}$ dan abrasi sebesar 13,99 $\mathrm{Ha}$ garis pantai Kabupaten Pinrang pada tahun 2013 adalah 98,02 garis pantai bertambah sepanjang 0,49 km menjadi $98,51 \mathrm{~km}$.

Hasil interpretasi garis pantai dari tahun 2013 sampai 2018 di overlay untuk mendapatkan peta perubahan garis pantai dari tahun 2013 sampai 2018. dalam kurun waktu 5 tahun terakhir (20132018). Luas perubahan garis pantai pada masing-masing kecamatan disajikan pada grafik berikut ini.

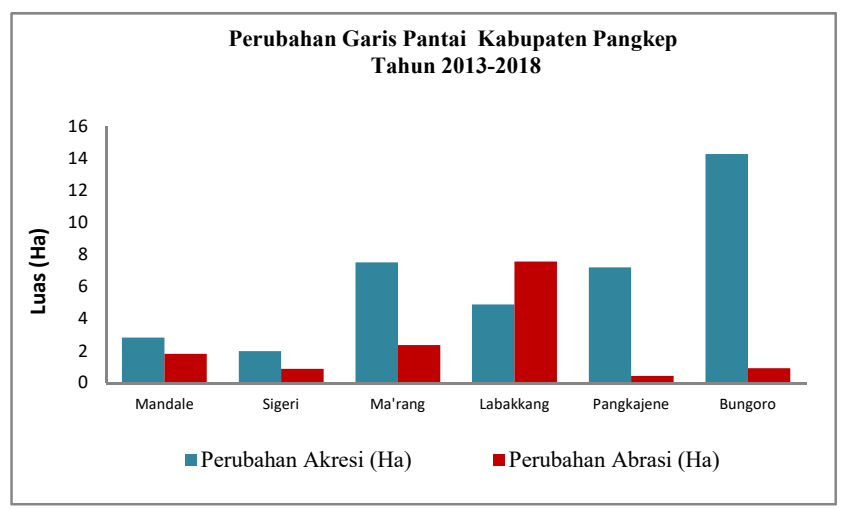

Gambar 2. Grafik Perubahan Garis Pantai Kabupaten Pangkep Tahun 2013-2018

Hasil analisis luas perubahan garis pantai yang disajikan pada Gambar 2 di atas terlihat bahwa kecamatan yang mengalami perubahan garis pantai berupa akresi yang sangat besar adalah Kecamatan Bungoro sebesar 14,29 Ha, disusul Ma'rang sebesar 7,53 Ha dan Pangkajene sebesar 7,21 Ha. Jika dilakukan rangking, maka kecamatan yang mengalami perubahan garis pantai berupa abrasi pantai yang sangat besar adalah Kecamatan Labakkang dengan luas perubahan sebesar 7,58 $\mathrm{Ha}$, disusul Ma'rang sebesar 2,36 $\mathrm{Ha}$ dan Mandale sebesar 1,81 Ha. Gambar 2 menunjukkan bahwa kecamatan yang tidak mengalami perubahan yang signifikan adalah kecamatan Sigeri dengan luas perubahan berupa akresi hanya 1,98 Ha 
dan abrasi 0,88 Ha dan sebaliknya kecamatan yang mengalami perubahan garis pantai yang sangat signifikan adalah Kecamatan Bungoro dengan luas perubahan garis pantai berupa akresi sebesar 14,29 Ha dan abrasi sebesar 0,92 Ha.

Berdasarkan suvey lapangan bahwa penyebab utama tingginya akresi di Kecamatan Bungoro dikarenakan adanya pemanfaatan lahan untuk pembangunan PLTU semen tonasa, pelabuhan, penanaman mangrove dan tingginya konversi lahan dari lindung ke area pertambakan serta adanya sedimentasi di sekitar muara sungai.

Pertama adanya penanaman mangrove dilakukan setiap tahun (selama \pm 10 tahun terakhir) baik dari pihak pemerintah maupun swasta. Kedua, tingginya konversi lahan dari kawasan lindung ke pertambakan (baik tambak garam maupun tambak ikan). Ketiga sedimentasi, pantai Biringkassi Kecamatan
Bungoro merupakan daerah pantai semitertutup.

Menurut Mustafa et al. (2006), peningkatan luas tambak di Kabupaten Pangkep yaitu dari 7.779 Ha menjadi 13.528 Ha atau terjadi pertambahan 5.749 Ha selama sebelas tahun dan terjadi penurunan luas sawah yang ada di kawasan pesisir dari $22.803 \mathrm{Ha}$ menjadi $18.280 \mathrm{Ha}$ akibat konversi sawah menjadi tambak.

\section{Perubahan Garis Pantai Kabupaten Pinrang}

Perubahan garis pantai di Kabupaten Pinrang sangat di pengaruhi arus susur pantai dan refraksi gelombang setiap tahunnya. Luas perubahan garis pantai Kabupaten Pinrang berupa akresi sebesar 158.15 Ha dan abrasi sebesar 41,88 Ha dalam kurun waktu 5 tahun terakhir. Luas perubahan garis pantai pada masingmasing kecamatan disajikan pada grafik berikut ini.

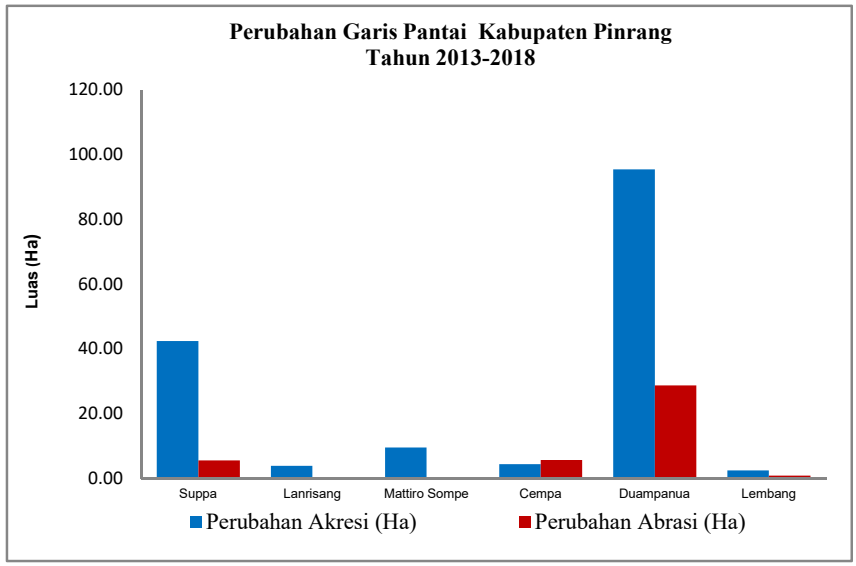

Gambar 3. Grafik Perubahan Garis Pantai Kabupaten Pinrang Tahun 2013-2018 
Berdasarkan luas perubahan garis pantai di Kabupaten Pinrang yang disajikan pada Gambar 3 diatas, terlihat bahwa kecamatan yang mengalami perubahan garis pantai berupa akresi yang sangat signifikan adalah Kecamatan Duampanua sebesar 95,32 Ha, disusul oleh Suppa sebesar 42,46 Ha dan Mattiro Sompe sebesar 9,53 Ha. Adapun kecamatan yang mengalami perubahan garis pantai berupa abrasi pantai yang sangat signifikan adalah Kecamatan Duampanua dengan luas perubahan sebesar 28,72 Ha, Cempa sebesar 5,74 Ha dan Suppa sebesar 5,62 Ha. Sebaliknya kecamatan yang tidak mengalami perubahan abrasi maupun akresi yang signifikan adalah kecamatan Lembang dan Lanrisang.

Berdarkan hasil interpretasi citra dan survei lapangan bahwa penyebab utama tingginya akresi dikarenakan adanya sedimentasi dari DAS Sungai Saddang dan adanya perluasan area tambak. Salah satu penyebab tingginya sedimentasi di sekitar muara Sungai Saddang dikerenakan terjadinya proses penumpukan material sedimen baik yang berasal dari laut maupun dari sungai, dan adanya perubahan pola pemnfaatan lahan seperti pengundulan hutan yang akan mempercepat proses sedimentasi maupun abrasi di sekitar pantai. Selain itu, parameter oseanografi (pasang surut, arus dan gelombang laut) juga berperan dalam perubahan atau pembentukan morfologi pantai di sekitar muara Sungai Saddang. Sedimentasi tersebut memberikan dampak negatif dan merupakan faktor utama penyebab degradasi sumberdaya yang ada di pesisir. Besarnya sedimentasi yang terjadi di muara Sungai Saddang mempengaruhi frekuensi banjir, sekaligus berdampak pada penurunan produksi tambak.

Menurut Paena (2008), tingginya frekuensi banjir yang terjadi di sekitar muara Sungai Saddang selama ini salah satu penyebabnya adalah cepatnya proses sedimentasi di muara tersebut. Menurut informasi dari masyarakat setempat bahwa pada Musim Timur (April-September) terjadi sedimentasi, sedangkan tingginya abrasi atau erosi disebabkan karena faktor alam (arus yang kuat dan gelombang besar) yang terjadi pada Musim Barat (Desember - Februari) dan juga karena lokasi pantai yang berhadapan langsung dengan laut lepas.

\section{Tingkat Akurasi Interpretasi Citra}

Untuk melihat apakah peta perubahan garis pantai yang telah didigitasi sesuai dengan hasil di lapangan atau tidak, diperlukan uji keakuratan. Uji keakuratan ini dilakukan dengan cara mengambil sampel di peta yang telah didigitasi kemudian mencocokan dengan data di lapangan. Dikarenakan waktu penelitian tidak sama dengan waktu terjadinya perekaman citra, maka peneliti mengambil beberapa titik yang memiliki waktu terdekat dengan pengamatan yakni tahun 2018. Titik yang diambil secara acak dengan jumlah 22 titik sampel. Survey lapangan dilakukan dengan bantuan Global Positioning System (GPS).

Berdasarkan hasil pengecekan titik sampel yang dilakukan di lapangan, titik 
sampel yang sesuai dengan hasil interpretasi dan mengalami perubahan yang tampak sebanyak 20 titik, sedangkan yang tidak jelas perubahannya sebanyak 2 titik sampel, sehingga diperoleh nilai akurasinya sebesar 90,9\%. Menurut Short (1982), bahwa nilai akurasi yang mempunyai tingkat ketelitian $\geq 80 \%$ sudah dianggap akurat.

\section{Karakteristik Hidrooseanografi}

Gelombang laut merupakan salah satu parameter oseanografi yang sangat penting, sering lebih dipertimbangkan daripada parameter lingkungan lainnya yang mempengaruhi bangunan pantai dan laut. Gelombang tersebut telah dijadikan prosedur standar dalam perencanaan bangunan pantai, berbeda dengan prosedur perencanaan untuk bangunan darat (Triana, 2008).

Berdasarkan hasil survey lapangan, gelombang yang terjadi pada lokasi penelitian disababkan beberapa faktor, diantaranya terjadi kerena pasut, tiupan angin dipermukaan laut dan gelombang terjadi karena bergeraknya kapal. Karakteristik gelombang yang ada diperairan pantai Pangkep dan Pinrang mengikuti angin musim yang sedang terjadi, hal ini diduga merupakan kondisi umum yang terjadi dilaut dimana energi gelombang dibentuk oleh energi angin. Dikaji dari musim, menurut Trenggono (2009) Musim Barat terjadi pada bulan Januari, Februari, Desember, Musim Peralihan I terjadi pada bulan Maret, April, Mei, Musim Timur terjadi pada bulan Juni, Juli, Agustus, dan Musim Peralihan II terjadi pada bulan September, Oktober, dan November.

Peranan arus terhadap dinamika perubahan pantai yaitu membawa sedimen sehingga peranan arus ini dapat menyebabkan sedimentasi atau akresi. Berdasarkan hasil pengamatan kecapatan arus diperoleh rata-rata kecepatan arus tertinggi terjadi pada bulan Februari dan Maret sekitar 15-40 cm/detik dan terendah terjadi bulan Juli sekitar 2-5 cm/detik di perairan Kabupaten Pinrang. Data tersebut menunjukkan bahwa kecepatan arus pada daerah penelitian relatif cepat.

Pengamatan pasang surut selama 30 hari pada tanggal 1 sampai 30 Juni 2018 dan diperoleh nilai surut terendah $0.6 \mathrm{~m}$ dan mencapai titik tertinggi $1.5 \mathrm{~m}$. Grafik pengamatan pasang surut menunjukkan bahwa tipe pasang surut di Pesisir Pantai Kabupaten Pangkep dan Pinrang adalah pasang surut harian ganda semidiurnal. Hal ini sesuai pernyataan Dahuri, dkk (1996) bahwa perairan kawasan timur Indonesia mempunyai tipe pasang surut harian ganda semidiurnal, dimana terjadi dua kali pasang dan dua kali surut dalam sehari dengan periode dan tinggi yang berbeda.

Persepsi masyarakat tentang kerusakan pantai akibat abrasi sebagian besar mengatakan bahwa kerusakan pantai yang terjadi diakibatkan oleh faktor alam (gelombang dan arus laut, serta rusaknya area mangrove) dan kerusakan terumbu karang berdasarkan hasil wawancara terhadap masyarakat sekitar. 
Arahan Strategi Pengelolaan Wilayah Pesisir Pantai Kabupaten Pangkep dan Pinrang

Unsur kekuatan (strength) antara lain: potensi wilayah pesisir strategis sebagai wilayah pelayaran dan sebagai daerah transit, potensi pemanfaatan penggunaan lahan sebagai lahan tambak cukup tinggi, potensi untuk pengembangan wisata pantai dan partisipasi masyarakat dalam pelestarian ekosistem mangrove dan kegiatan bersih-bersih pantai. Unsur kelemahan (weakness) antara lain: terjadinya abrasi dan akresi pantai, kualitas SDM masih rendah, konversi lahan dari lindung ke budidaya dan kurangnya kepedulian masyarakat terhadap lingkungan. Unsur peluang (opportunity) antara lain: pengembangan wisata pantai dan tambak mendorong peningkatan ekonomi, adanya program dan dukungan masyarakat, pemerintah dan lembaga terhadap pengelolaan ekosistem mangrove. Unsur ancaman (threat) antara lain: pembukaan lahan tambak tanpa adanya tindak lanjut perbaikan lahan, kemunkinan terjadinya abrasi/erosi pantai dan sedimentasi pantai yang bertambah setiap tahun dan potensi pencemaran laut dari pelabuhan dan pemukiman serta illegal fishing yang dapat menyebabkan gangguang lingkungan.

Berdasarkan faktor internal dan eksternal tersebut, maka disusun rencana strategi pengelolaan pesisir pantai Kabupaten Pangkep dan Pinrang dengan metode SWOT dan ditetapkan 7 (tujuh) strategi terbaik antara lain: (1) Membuat daerah khusus pengamanan pantai dan konservasi pantai secara alami, terutama sebagai langkah pengendalian sedimentasi, erosi abrasi dan akresi; (2) Penegakan hukum dan penguatan kelembagaan; (3) Memberikan alokasi ruang khusus untuk pengaman dan perlingdungan pantai terutama daerah-daerah yang sering menjadi transit dan bongkar muat perdagangan dan jalur-jalur pelayaran; (4) Peningkatan kualitas SDM masyarakat sekitar pesisir pantai; (5) Pengembangan sistem tambak berbasis konservasi yang baik; (6) peningkatan partisipasi masyarakat dan stakeholder lainnya dalam kegiatan pengelolaan pesisir pantai; (7) Pembatasan lahan budidaya pada kawasan konservasi alami terutama untuk daerah terbangun di wilayah pesisir

\section{KESIMPULAN}

Berdasarkan hasil penelitian yang telah dilakukan di wilayah pesisir pantai Kabupaten Pangkep dan Pinrang, maka dapat disimpulkan sebagai berikut:

1. Luas perubahan garis pantai yang terjadi di Kabupaten Pangkep sebesar 38.74 Ha berupa akresi dan $13.99 \mathrm{Ha}$ berupa abrasi, sedangkan untuk Kabupaten Pinrang luas perubahan garis pantai sebesar $158.15 \mathrm{Ha}$ yang mengalami akresi dan 41.88 Ha berupa abrasi.

2. Gelombang, arus dan pasang surut yang terjadi di pesisir pantai Kabupaten Pangkep dan Pinrang berpengaruh terhadap tingkat perubahan garis pantai baik abrasi maupun akresi. 
3. Strategi pengelolaan pesisir pantai Kabupaten Pangkep dan Pinrang, yaitu; membuat daerah khusus pengamanan pantai dan konservasi pantai secara alami; penegakan hukum dan penguatan kelembagaan; memberikan alokasi ruang khusus untuk pengaman dan perlingdungan pantai; dan peningkatan kualitas SDM masyarakat sekitar pesisir pantai.

\section{SARAN}

1. Sebaiknya penentuan garis pantai juga berdasarkan nilai ketinggian dari hitungan pasang surut agar memiliki nilai lebih tinggi dan lebih dapat dilihat perbedaannya. Karena jika mendigitasi sesuai batas air pada waktu perekaman yang berbeda maka posisi garis pantai akan jauh berbeda antara data yang satu dengan yang lainnya.

2. Bagi pihak pemerintah Kabupaten Pangkep dan Pinrang untuk melakukan kajian mitigasi bencana abrasi dan sedimentasi pantai yang ada di pesisir pantai Kabupaten Pangkep dan Pinrang

\section{UCAPAN TERIMA KASIH}

Penulis mengucapkan terima kasih kepada Pemerintah Kabupaten Pangkep dan Kabupaten Pinrang yang telah memberikan dukungan berupa data-data dalam melaksanakan penelitian tesis ini, pembimbing dan para reviewer yang telah banyak memberikan masukan dan komentar untuk memperbaiki tulisan ini.

\section{DAFTAR PUSTAKA}

Chand and Acharya P. 2010. Shoreline change and sea level rise along coast of Bhitarkanika wildlife sanctuary, Orissa: An analytical approach of remote sensing and statistical techniques. Int J Geom \& Geos, 1 (3):436-455

Dahuri, H.R., Rais, J., Ginting, S.P., dan Sitepu, M.J., 1996. Pengelolaan Sumber Daya Wilayah Pesisir dan Lautan Secara Terpadu, PT Pradnya Paramita, Jakarta.

Mustafa A., Utojo, Hasnawi, \& Rachmansyah. 2006. Validasi Data Luas Lahan Budidaya Tambak di Kabupaten Maros dan Pangkep Provinsi Sulawesi Selatan dengan Menggunakan Teknologi Penginderaan Jauh dan Sistem Informasi Geografis. Pusat Riset Perikanan Budidaya, Jakarta. J. Ris. Akuakultur, 3(1): 419-430.

Notoatmodjo, S., 2002. Metodologi Penelitian Kesehatan, Edisi Revisi, Jakarta: PT Rineka Cipta. Hal. 35, 125.

Paena, M. 2008. Pemanfaatan Teknik Penginderaan Jauh dan Sistem Informasi Geografis untuk Memantau Perubahan Profil Pantai Akibat Sedimentasi di Muara Sungai Saddang Kabupaten Pinrang, Sulawesi Selatan. Balai Riset Perikanan Budidaya Air Payau, Maros. Media Akuakultur Volume 3 Nomor 2 Tahun 2008: 175-180. 
Rais, 2000. Kajian Kerawanan dan Dinamika Wilayah Pesisir. Materi Kuliah pada Program Studi Pengelolaan Sumberdaya Pesisir dan Lautan Program Pascasarjana IPB, 92 hal

Short, N. M. (1982). Landsat Tutorial Workbook-Basics of Satellite Remote Sensing. NASA, Washington DC.

Trenggono M. 2009. Transformasi gelombang dan pengaruhnya terhadap dinamika pantai muara Ajkwa Tahun 1993-2007. [Tesis]. Bogor: Fakultas Perikanan dan Ilmu Kelautan. Institut Pertanian Bogor.

Triana, Y. 2008. Longshore current yang ditimbulkan oleh transformasi gelombang di Eretan Kulon, Indramayu. Bogor : IPB. Tesis. Tidak Dipublikasikan

Pantai Edisi Kedua. Yogyakarta:

UGM. Hal: 129. 